\title{
SORGHUM
}

\section{Genotype and Environment Effects on Dynamics of Harvest Index during Grain Filling in Sorghum}

\author{
Graeme L. Hammer* and Ian J. Broad
}

\begin{abstract}
An approach based on a linear rate of increase in harvest index (HI) with time after anthesis has been used as a simple means to predict grain growth and yield in many crop simulation models. When applied to diverse situations, however, this approach has been found to introduce significant error in grain yield predictions. Accordingly, this study was undertaken to examine the stability of the HI approach for yield prediction in sorghum [Sorghum bicolor (L.) Moench]. Four field experiments were conducted under nonlimiting water and $\mathbf{N}$ conditions. The experiments were sown at times that ensured a broad range in temperature and radiation conditions. Treatments consisted of two population densities and three genotypes varying in maturity. Frequent sequential harvests were used to monitor crop growth, yield, and the dynamics of HI. Experiments varied greatly in yield and final HI. There was also a tendency for lower HI with later maturity. Harvest index dynamics also varied among experiments and, to a lesser extent, among treatments within experiments. The variation was associated mostly with the linear rate of increase in $\mathrm{HI}$ and timing of cessation of that increase. The average rate of $\mathrm{HI}$ increase was $0.0198 \mathrm{~d}^{-1}$, but this was reduced considerably $(0.0147)$ in one experiment that matured in cool conditions. The variations found in $\mathrm{HI}$ dynamics could be largely explained by differences in assimilation during grain filling and remobilization of preanthesis assimilate. We concluded that this level of variation in $\mathrm{HI}$ dynamics limited the general applicability of the $\mathrm{HI}$ approach in yield prediction and suggested a potential alternative for testing.
\end{abstract}

$\mathrm{C}$ ROP SIMULATION MODELS are often deficient in their predictions of grain growth. Hammer and Muchow (1994) developed a crop model for sorghum that accounted for $94 \%$ of the variation in total biomass, but only $64 \%$ of the variation in grain yield, when tested using data sets spanning a broad range of environments. Their testing procedure showed a weakness in using an approach based on HI dynamics to predict grain growth and yield. The HI approach used a linear increase in HI with time from shortly after anthesis until two-thirds of the time between anthesis and physiological maturity had elapsed or the maximum $\mathrm{HI}$ of 0.55 had been reached (Hammer and Muchow, 1994). This approach was based on the concept developed in soybean [Glycine $\max ($ L.) Merr.] by Spaeth and Sinclair (1985) from their observation of stability in HI dynamics for a small number of experiments. The approach had proved useful in other crops, such as peanut (Arachis hypogaea L.) (Hammer et al., 1995), maize (Zea mays L.) (Mu-

G.L. Hammer and I.J. Broad, Agric. Prod. Syst. Res. Unit, Queensland Dep. of Primary Industries, Toowoomba, QLD 4350, Australia. G.L. Hammer, School of Land and Food Sci., The Univ. of Queensland, Brisbane, QLD 4072, Australia. Received 2 Mar. 2002. *Corresponding author (graeme.hammer@dpi.qld.gov.au).

Published in Agron. J. 95:199-206 (2003). chow and Sinclair, 1991), and sunflower (Helianthus annuus L.) (Chapman et al., 1993).

Deficiencies in the HI approach, however, may be associated with use of a constant rate of $\mathrm{HI}$ increase across diverse environments, particularly for cool temperatures, and possible variation in maximum $\mathrm{HI}$ or timing of cessation of linear increase in $\mathrm{HI}$ associated with other factors, such as crop maturity. In studies on HI dynamics in sunflower, Bange et al. (1998) showed that while rate of increase in $\mathrm{HI}$ was linear, the rate decreased with low temperature during grain filling. They also noted that duration of the period from anthesis to the onset of linear increase in HI (i.e., lag phase) varied and was inversely related to temperature. However, rate of increase in $\mathrm{HI}$ did not differ among levels of $\mathbf{N}$ for sunflower (Bange et al., 1998) or sorghum (Muchow, 1988).

As crop models need to be applied across a diverse range of environments in exploring strategies to improve crop management, such as sowing date (e.g., Muchow et al., 1994), it is important that they incorporate robust approaches to growth and yield prediction. Accordingly, this study was undertaken to examine the stability of the HI approach for yield prediction in sorghum. Field experiments were conducted using a range of genotypes and growing conditions, and crop growth, yield, and HI dynamics were monitored and analyzed.

\section{MATERIALS AND METHODS}

\section{Field Experiments}

Four experiments were conducted at Lawes $\left(27^{\circ} 34^{\prime} \mathrm{S}\right.$, $152^{\circ} 20^{\prime} \mathrm{E}$; altitude $90 \mathrm{~m}$ above sea level) in southeastern Queensland, Australia, on a Lawes brown black clay loam, which is a moderately fertile deep alluvial, weakly cracking vertisol (Typic Chromustert) that was well drained. The experiments were sown on 27 Sept. 1993, 28 Jan. and 10 Nov. 1994. and 12 Jan. 1995. Meteorological conditions were recorded at the experimental site using a data logger with appropriately calibrated sensors.

In the first two experiments, three sorghum hybrids differing in maturity formed the main treatments. Hybrids Pioneer S34, RS610, and RS671 were chosen for their contrasting phenology: Pioneer S34 has quick maturity, RS671 medium late maturity, and RS610 intermediate maturity. In the third and fourth experiments, the two sorghum hybrids differing most in maturity (Pioneer S34 and RS671) were grown at two levels of plant population-16 and 8 plants $\mathrm{m}^{-2}$. The density used in the first two experiments corresponded with the highdensity treatment in the latter two experiments. Plots mea-

Abbreviations: A-M, anthesis to physiological maturity; E-A, emergence to anthesis; HI, harvest index; LAI, leaf area index. 
sured 28 by $4 \mathrm{~m}$ (eight rows). A randomized block design with three replications was used for each experiment.

Before sowing, $\mathrm{K}$ at $5 \mathrm{~g} \mathrm{~m}^{-2}$ as muriate of potash, $\mathrm{P}$ at $3 \mathrm{~g}$ $\mathrm{m}^{-2}$ as single superphosphate, copper sulfate at $0.3 \mathrm{~g} \mathrm{~m}^{-2}$, and zinc sulfate at $0.3 \mathrm{~g} \mathrm{~m}^{-2}$ were applied as a broadcast application. At sowing, $120 \mathrm{~kg} \mathrm{ha}^{-1} \mathrm{~N}$ was broadcast as urea, with a further $60 \mathrm{~kg} \mathrm{ha}^{-1}$ applied at initiation and anthesis as a split application (total $240 \mathrm{~kg} \mathrm{ha}^{-1} \mathrm{~N}$ ). The first two experiments were sown following the removal of a cover crop of oat (Avena sativa $\mathrm{L}$.). Before the latter two experiments, the site had been fallow since a sorghum crop the previous summer.

All sorghum seed was dressed with Concep [1,3-dioxolan2-yl-methoxy imano (phenyl) acetonitrile] (Ciba Geigy, Basel, Switzerland) at $1.25 \mathrm{mg} \mathrm{g}^{-1}$ for protection against pre-emergence herbicides. The crop was sown into cultivated soil, using a precision planter, in $50-\mathrm{cm}$ rows and thinned to 16 or 8 plants $\mathrm{m}^{-2}$ at $2 \mathrm{wk}$ after sowing. Immediately after sowing, metolachlor [2-chloro- $N$-(2-ethyl-6-methylphenyl)- $N$-(2-methoxy-1-methylethyl)acetamide] at $180 \mathrm{mg} \mathrm{m}^{-2}$ and atrazine (6-chloro- $N^{2}$-ethyl$N^{4}$-isopropyl-1,3,5-triazine-2,3-diamine) at $125 \mathrm{mg} \mathrm{m}^{-2}$ were applied, and this gave good weed control, with the exception of two weed species in the third experiment. Dicamba (3,6-dichloro$O$-anisic acid) was applied at $16 \mathrm{mg} \mathrm{m}^{-2}$ at 3 wk after sowing to enable control of those species. Irrigation was applied regularly to keep the soil water profile full so that crops developed under non-water-limiting conditions.

When necessary, heliothis (Helicoverpa armigera) and sorghum midge (Stenodiplosis sorghicola) were controlled by applications of Permethrin [3-phenoxybenzyl(1RS)-cis,trans-3-(2,2dichlorovinyl)-2,2-dimethylcyclopropanecarboxylate] at $12 \mathrm{mg}$ $\mathrm{m}^{-2}$ or Endosulfan $(6,7,8,9,10,10$-hexachloro-1,5,5a,6,9,9a-hexahydro-6,9-methano-2,4,3-benzodioxathiepin 3-oxide) at $73.5 \mathrm{mg}$ $\mathrm{m}^{-2}$. Initially, monocrotophos [dimethyl $(E)-1$-methyl-2-(methylcarbamoyl)vinyl phosphate] at $26 \mathrm{mg} \mathrm{m}^{-2}$ was used in the first experiment but caused minor leaf burn in two hybrids and was discontinued. Leaf rust was controlled by applications of Mancozeb [manganese ethylenebis(dithiocarbamate) (polymeric) complex with zinc salt] and wettable $S$ at 18 and $42 \mathrm{mg}$ $\mathrm{m}^{-2}$ respectively. There was negligible damage to the photosynthetic leaf surface throughout growth.

\section{Measurements}

Timing of floral initiation was determined by dissection of five plants every second day, commencing shortly after thinning. Initiation was deemed to have occurred once the first primary floral primordia were visible on the differentiating shoot apex (Stage 3 of Moncur, 1981). Timing of anthesis (exertion of anthers on more than $50 \%$ of the panicle) was established by scoring five tagged plants in the inner rows of each plot. Timing of maturity was taken as the presence of black layer (Eastin et al., 1973) on $90 \%$ of grains on the same five plants plus an additional five plants in an adjacent central row.

Biomass accumulation was determined by quadrat sampling at initiation, midway between initiation and anthesis, at anthesis, and then at 4- to 6-d intervals until maturity. At each harvest, plants in a $2.0-\mathrm{m}^{2}$ quadrat were cut at ground level from the inner rows of each plot. A representative subsample of 10 plants was taken, and the fresh weights of the subsample and the remainder of the sample were determined. Net aboveground biomass was determined after drying the subsample at $80^{\circ} \mathrm{C}$. The panicles from the subsample were threshed, and grain yield was determined. Grain size was determined from the weight of 200 grains. All data are presented on an oven-dry basis. Harvest index was calculated as the ratio of grain yield to net aboveground biomass. Green leaf area was determined on a further subsample of three to five plants using a leaf area meter. The specific leaf area of that subsample was computed as the leaf area per unit leaf dry weight, and leaf area index (LAI) for the plot was calculated as the product of specific leaf area and leaf mass per unit area. The green leaf at anthesis and green leaf and grain at maturity were analyzed for $\mathrm{N}$ concentration using method 7A1 for total $\mathrm{N}$ analysis (Rayment and Higginson, 1992).

Leaf growth and senescence were measured by counting the total and senesced (leaf area $>50 \%$ senesced) leaves on five tagged plants (main culm plus tillers) on a weekly basis. The origin of tiller appearance with regards to the main culm was also recorded during Exp. 3 and 4. The size of individual leaves was measured using a leaf area meter on samples harvested from additional tagged plants during the crop cycle (three times of sampling).

Radiation interception was measured by placing a tube solarimeter (Type TSL, Delta-T Devices, Cambridge, UK) diagonally across the two inner rows of each plot at ground level. These solarimeters were used to record the radiation $(0.35$ to $2.5 \mu \mathrm{m})$ transmitted through the crop canopy at 5-min intervals. Hourly averages were logged. Another tube solarimeter was placed above the crop, and the incident radiation was recorded. Daily totals and individual tube calibration factors were used to calculate the fraction of incident radiation intercepted in each plot. Since the readings from individual solarimeters were found to vary by up to $20 \%$ from the nominal calibration, the absolute incident radiation was recorded with a pyranometer (Li 200S, LI-COR, Lincoln, NE). The amount of radiation intercepted was calculated as the cumulative product of the daily fraction of incident radiation intercepted and the absolute incident radiation.

\section{Data Analysis}

For each plot, HI measured at each harvest after anthesis was plotted against days after anthesis. Broken linear equations were fitted to these data to determine the start and end of the period of linear HI increase, the rate of HI increase, and final HI (Fig. 1). Analyses of variance were conducted on these HI attributes as well as on crop growth, grain yield, and phenology to determine treatment effects within each experiment. A pooled analysis of variance was conducted across

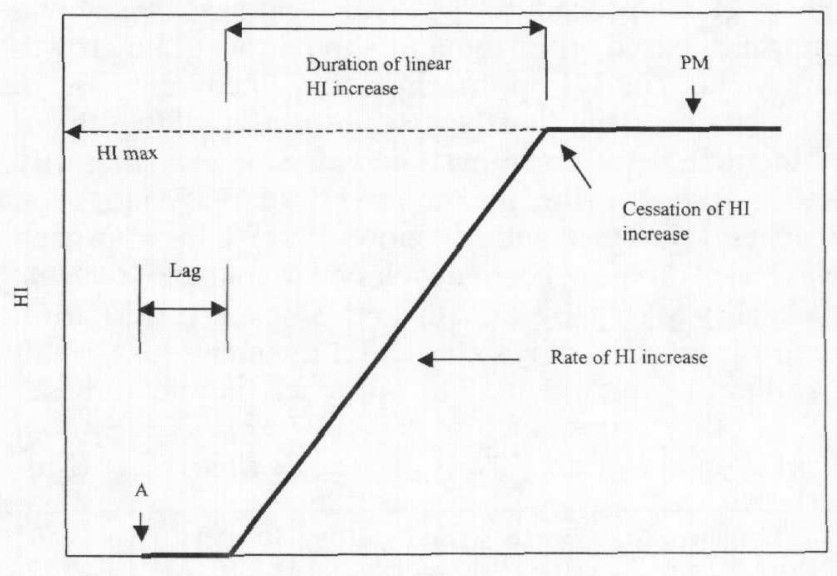

Days after anthesis

Fig. 1. Schematic of broken linear equations for the relationship between harvest index (HI) and days after anthesis. Timing of anthesis (A), duration of lag phase to start of linear increase in HI (Lag), rate and duration of linear increase in $\mathrm{HI}$, timing of cessation of HI increase, maximum HI (HI max), and timing of physiological maturity (PM) are indicated. 
experiments. All analyses were conducted using Genstat [Release 4.21 (2001), Lawes Agricultural Trust, Rothamsted Experimental Station].

\section{RESULTS AND DISCUSSION \\ Meteorological Conditions}

The average maximum and minimum temperatures for Exp. 1 and 2 were very similar at 29 and $15^{\circ} \mathrm{C}$ and 28 and $15^{\circ} \mathrm{C}$, respectively (Fig. 2). However, Exp. 1 was grown under increasing temperature conditions, whereas Exp. 2 experienced decreasing temperatures leading to cooler conditions during grain filling. The effect was similar although less marked for Exp. 3 and 4, with average maximum and minimum temperatures slightly higher at 32 and $18^{\circ} \mathrm{C}$ and 30 and $17^{\circ} \mathrm{C}$, respectively. Average incident radiation was $22,17,22$, and $20 \mathrm{MJ}$ $\mathrm{m}^{-2}$ for Exp. 1 to 4 , respectively.
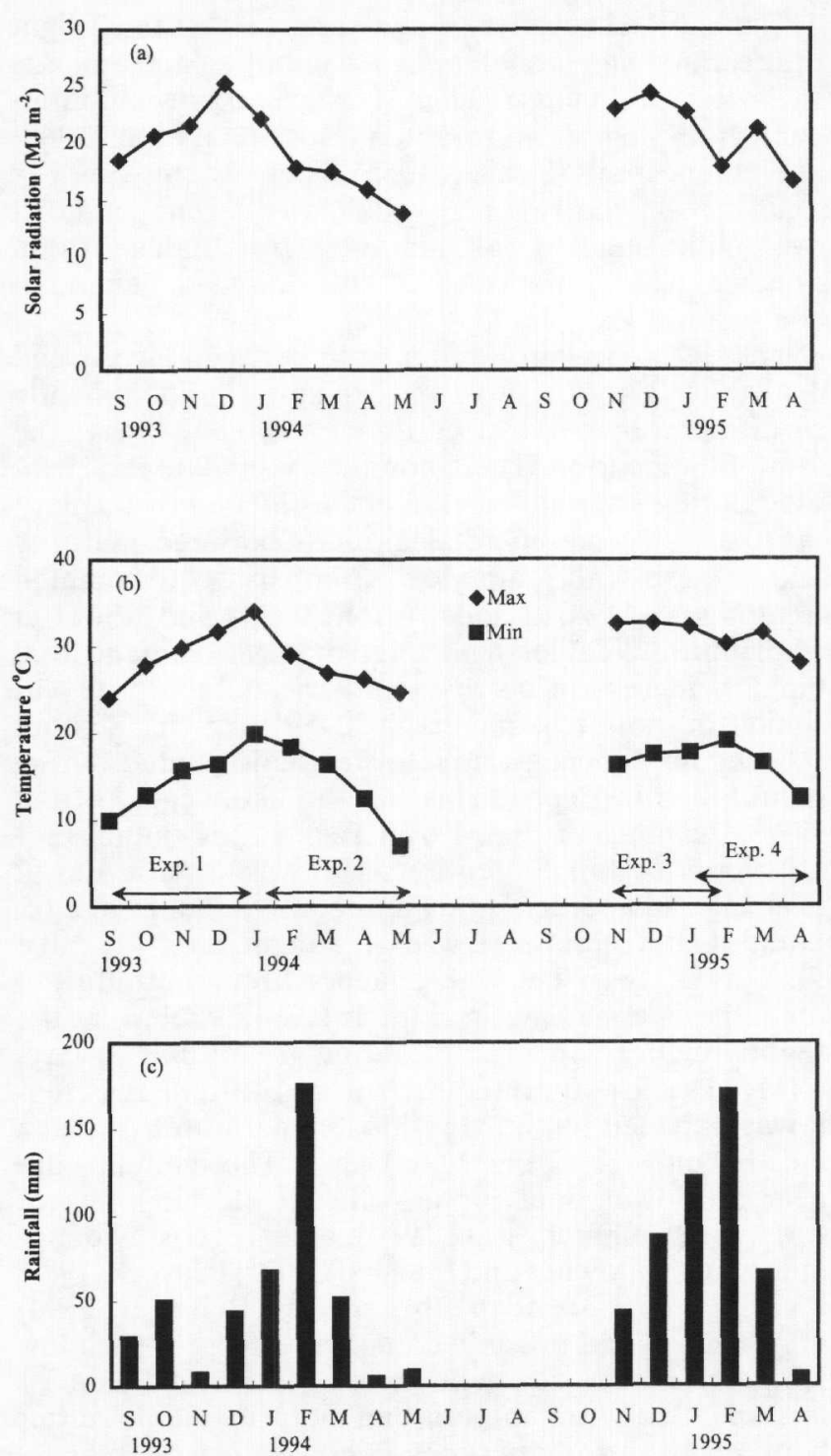

Fig. 2. Monthly means of (a) daily solar radiation and (b) maximum and minimum temperature and (c) monthly totals of rainfall at Gatton for the time period of the four field experiments. The duration of the experiments is shown in (b). Data for the period between experiments (June 1994 to October 1994) are not shown.

\section{Crop Development}

The time from emergence to anthesis (E-A) differed by 5 to $9 \mathrm{~d}$ among hybrids across all experiments in the manner expected: hybrid S34 was quickest, RS610 intermediate, and RS671 slowest (Table 1). Duration of E-A was longer in Exp. 1 and 2 as a consequence of the cooler conditions during this period for those experiments (Fig. 1). The time from anthesis to physiological maturity (A-M) differed significantly among hybrids, but differences were small except in Exp. 2 and 4 where the later-maturing hybrid took 7 to $9 \mathrm{~d}$ longer than the early maturing hybrid. The duration of A-M was longer in these experiments due to the cool temperatures at the end of the grain-filling period (Fig. 1). This was particularly accentuated for the late-maturing hybrid, which reached anthesis about a week later than the early maturing hybrid, thus exposing it to even lower temperatures. The differences observed in phenology were consistent with known effects of temperature and photoperiod (data not shown) on duration of E-A and of temperature on duration of A-M (Hammer et al., 1989; Hammer and Muchow, 1994). The differences in duration of A-M associated with density (1 to $2 \mathrm{~d}$; Table 1) may have been a consequence of interplant competition effects, but the magnitude was minor and not of practical significance in this study.

\section{Grain Yield, Total Biomass, and Harvest Index}

Grain yield varied from 4700 to $9400 \mathrm{~kg} \mathrm{ha}^{-1} \mathrm{de}-$ pending on treatment and experiment (Table 2). There was large and significant variation in yield among experiments, despite all being grown under nonlimiting water and nutrient conditions. For the treatments common to all four experiments (Pioneer S34 and RS671 at 16 plants $\mathrm{m}^{-2}$ ), average yield in each of the four experiments was $8750,4950,8350$, and $6050 \mathrm{~kg} \mathrm{ha}^{-1}$, respectively. The results for Exp. 2 and 4 were well below the expectation for potential yield of sorghum while those for Exp. 1 and 3 approximated expectations (Hammer et al., 1996). Significant differences in grain yield among hybrids were found only in Exp. 3 and 4. The late-maturing hybrid had significantly higher grain yield than the early maturing hybrid in Exp. 4 but was significantly lower yielding in Exp. 3. Plant density had no significant effect on grain yield in individual experiments due to the compensating effect of enhanced tillering at the lower density. Over all experiments (pooled analysis), however, the density effect was significant with greater yield at high density.

Grain yield can be defined as the product of total biomass and HI. The high yields in Exp. 1 and 3 were associated with high biomass production (14.3-17.6 t ha $^{-1}$ ) (Table 3 ) and high HI (0.47-0.57) (Table 4). These HI values were close to the maximum $\mathrm{HI}$ of 0.55 that has been reported as reflecting the genetic potential of most current sorghum hybrids (Hammer and Muchow, 1994). The low yields in Exp. 2 and 4 were related to low total biomass at maturity in both cases (10.3-13.3 $\mathrm{t} \mathrm{ha}^{-1}$ ) (Table 3). Only in Exp. 2, however, did lower values of $\mathrm{HI}(0.42$ to 0.46$)$ (Table 4 ) also contribute 
Table 1. Duration of the developmental phases emergence to anthesis (E-A) and anthesis to physiological maturity (A-M) for the treatments in each of the four experiments. The density associated with each treatment is included in parentheses after the hybrid name. Not all treatments were included in each experiment.

\begin{tabular}{|c|c|c|c|c|c|c|c|c|}
\hline \multirow[b]{3}{*}{ Hybrid (density, plants $\mathbf{m}^{-2}$ ) } & \multicolumn{8}{|c|}{ Experiment $\dagger$} \\
\hline & \multicolumn{2}{|c|}{1} & \multicolumn{2}{|c|}{2} & \multicolumn{2}{|c|}{3} & \multicolumn{2}{|c|}{4} \\
\hline & E-A & A-M & E-A & A-M & E-A & A-M & E-A & A-M \\
\hline & & & & $-\mathbf{D}$ & d & & & \\
\hline Pioneer S34 (16) & 56.7 & 34.7 & 55.0 & 39.7 & 47.0 & 34.7 & 49.3 & 36.0 \\
\hline Pioneer S34 (8) & - & - & - & - & 47.0 & 33.0 & 49.7 & 37.0 \\
\hline RS610 (16) & 58.7 & 35.3 & 60.3 & 45.0 & - & - & - & - \\
\hline RS671 (16) & 65.3 & 32.3 & 63.0 & 48.7 & 56.0 & 35.7 & 54.0 & 45.0 \\
\hline RS671 (8) & - & - & - & - & 56.7 & 34.0 & 55.3 & 44.0 \\
\hline LSD hybrid $(0.05)$ & 1.3 & 2.0 & 1.5 & 3.7 & 0.9 & NS & 1.3 & 0.9 \\
\hline LSD density $(0.05)$ & - & - & - & $\ldots$ & NS & 1.5 & NS & NS \\
\hline LSD hybrid $\times$ density $(0.05)$ & - & - & - & - & NS & NS & NS & 1.3 \\
\hline
\end{tabular}

+ For both E-A and A-M, significant (0.05) effects from pooled analysis across experiments were found for experiment (LSD = 1.4 and 1.2, respectively), hybrid (LSD $=0.9$ and 1.3, respectively), and experiment $\times$ hybrid (LSD $=1.4$ and 1.9, respectively). In addition, for E-A, significant (0.05) effects were found for density $($ LSD $=0.7)$ and hybrid $\times$ density $(L S D=1.0)$

substantially to the lower yield outcome, such that yields were lowest in this experiment.

The differences in grain yield manifested through differences in total biomass and $\mathrm{HI}$ can be examined using the source-sink framework that considers contributions from both assimilation during grain filling and remobilization of preanthesis assimilate. In sorghum, this source-sink framework is exemplified by the studies of Fischer and Wilson (1975). The differences in total biomass at maturity among experiments in this study, and hence the major differences in yield, may be explained predominantly by differences in assimilation during the grain-filling period. Differences in assimilation during this period were consistent with the observation that total biomass at anthesis did not differ as much among experiments as total biomass at maturity (Table $3)$. Although total biomass at anthesis was mostly lower in Exp. 2 and 4 (than in Exp. 1 and 3), the relative differences were not as great as they were for total biomass at maturity. Hence, there was additional assimilation during grain filling in Exp. 1 and 3 that accounted for the higher biomass and yield in those experiments. The additional assimilation was associated with higher incident radiation, higher temperature (Fig. 1), and slightly greater LAI (Table 3 ) in those experiments. It is likely that the environmental effects were the dominating factors though as LAI was sufficiently high in all cases to intercept most of the incident radiation. Grain

Table 2. Grain yield for the treatments in each of the four experiments. The density associated with each treatment is included in parentheses after the hybrid name. Not all treatments were included in each experiment.

\begin{tabular}{|c|c|c|c|c|}
\hline \multirow[b]{2}{*}{ Hybrid (density, plants $\mathrm{m}^{-2}$ ) } & \multicolumn{4}{|c|}{ Experiment +} \\
\hline & 1 & 2 & 3 & 4 \\
\hline & & Grain y & $\mathbf{k g ~ h a}^{-}$ & \\
\hline Pioneer S34 (16) & 9100 & 4700 & 8900 & \\
\hline Pioneer S34 (8) & - & - & 8100 & $\mathbf{5 5 0 0}$ \\
\hline RS610 (16) & 9400 & 4800 & - & \\
\hline RS671 (16) & 8400 & 5200 & 7800 & \\
\hline RS671 (8) & - & - & 7100 & \\
\hline LSD hybrid $(0.05)$ & NS & NS & 900 & \\
\hline LSD density $(0.05)$ & - & - & NS & NS \\
\hline
\end{tabular}

† Significant (0.05) effects from pooled analysis across experiments were found for experiment $($ LSD $=700)$, density $($ LSD $=500)$, and experiment $\times$ hybrid $($ LSD $=1000)$. number was higher in Exp. 1 and 3 than in Exp. 2 and 4 (Table 5). This reflected the enhanced levels of light interception and growth between initiation and anthesis in those experiments (Table 3 ), which is known to influence grain number in sorghum (Rosenthal et al., 1989) and other cereals (Fischer, 1985). There was also greater grain size in the two high-yielding experiments, however, indicating that sink limitation (from reduced grain number) was not the cause of lower biomass increment and yield in Exp. 2 and 4.

The differences in HI and yield between Exp. 2 and 4 (Tables 2 and 4) may be explained predominantly by differences in redistribution of assimilate during the grain-filling period. The amount of assimilate redistributed during grain filling could be estimated by comparing the difference in total biomass between maturity and anthesis with grain yield. Comparing the common treatments in Exp. 2 and 4 (Pioneer S34 and RS671 at 16 plants $\mathrm{m}^{-2}$; Table 3 ) indicated that, although the total biomass increment between anthesis and maturity was similar in those treatments (4630-5010 kg ha-1), about $1000 \mathrm{~kg} \mathrm{ha}^{-1}$ more assimilate was redistributed during grain filling in Exp. 4. This was the likely cause of the yield advantage of Exp. 4 over Exp. 2. The findings for $\mathrm{HI}$ supported this contention as HI was lower in Exp. 2 (Table 4). In addition, grain number was similar in Exp. 2 and 4, but grain size was greater in Exp. 4 (Table $5)$. This is consistent with enhanced remobilization of preanthesis assimilate in Exp. 4. It is possible that the slightly higher temperature during grain filling in Exp. 4 (Fig. 1) allowed remobilization to continue, whereas it was impeded by the very low temperatures (minima mostly below $12^{\circ} \mathrm{C}$; Fig. 1) in Exp. 2 . These minima are near the lower limit for growth and development of sorghum (Hammer et al., 1989), and there is evidence in sorghum (Downes and Marshall, 1971; Peacock, 1982; McWilliam, 1983) and in other species (Bell et al., 1994) of restrictive and possibly damaging effects of such low temperatures on growth processes. As the total biomass increment between anthesis and maturity did not differ between the two experiments, however, it is unlikely that the more severe chilling temperatures experienced in Exp. 2 were sufficiently low to have triggered damage to the photosynthetic system (Bell et al., 1994; McWilliam, 1983; Hall, 2001). 
Table 3. Growth characteristics for hybrid and density treatments in Exp. 1 through 4. The sum of intercepted radiation is measured from the harvest date at initiation to the harvest day at either anthesis or maturity.

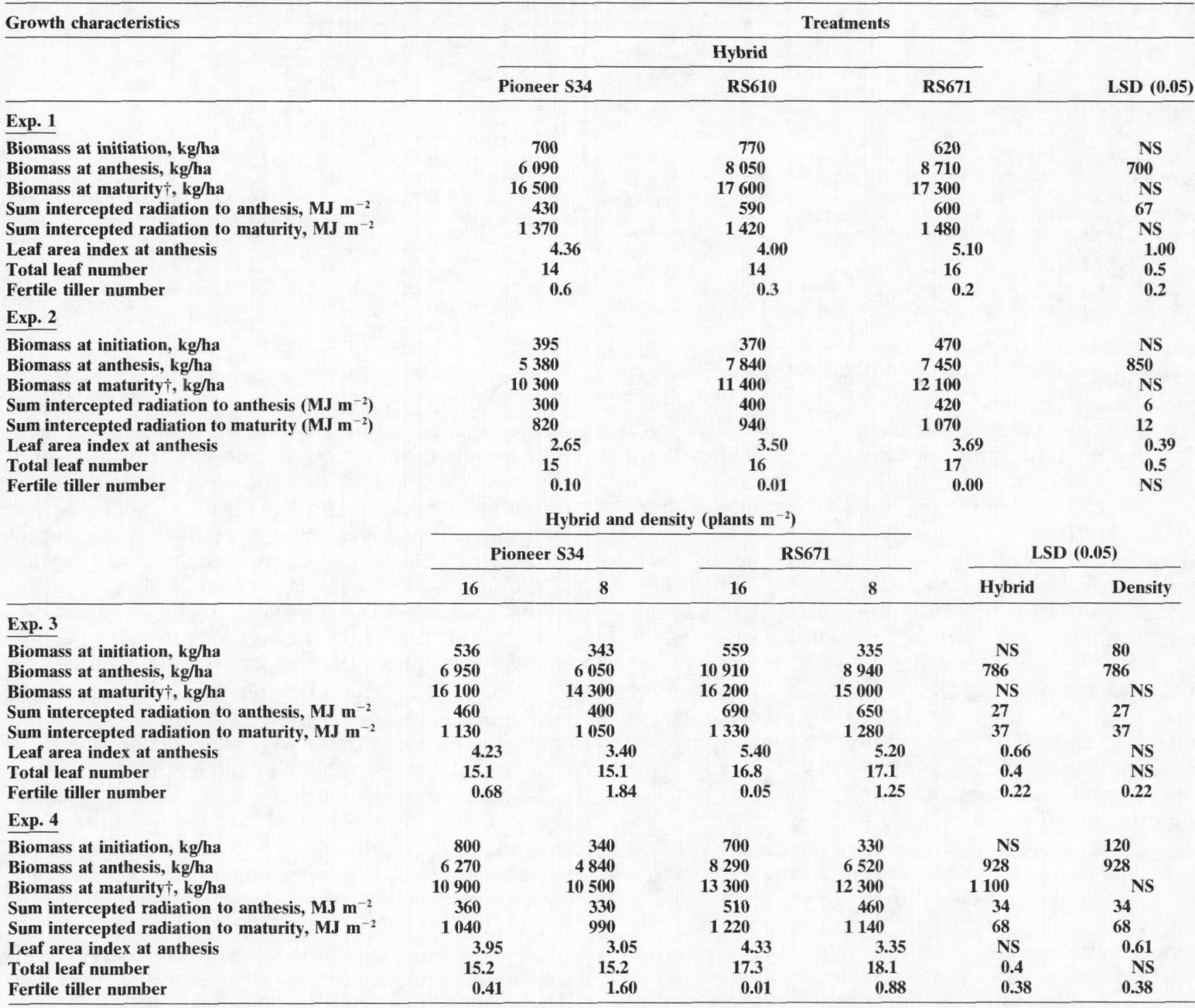

$\dagger$ For biomass at maturity, significant $(0.05)$ effects from pooled analysis across experiments were found for experiment $($ LSD $=1145)$, hybrid $($ LSD $=$ 1230), and density (LSD $=998)$.

There was a tendency for lower final HI (Table 4) to be associated with late maturity, but this was not totally reflected in yield differences (Table 2). In Exp. 1, differences in final HI (significantly lower in late maturing) were compensated by opposing (but not significant) trends in biomass (Table 3 ) so that final yield did not differ significantly among hybrids. Neither yield nor final HI differed significantly among hybrids in Exp. 2. In Exp. 3, the significantly lower HI of the late-maturing type was reflected in lower grain yield, whereas in Exp. 4 , although HI was significantly lower in the late-maturing type, it yielded significantly more due to opposing (but not significant) trends in biomass. These differences in final HI with hybrid maturity were associated with differences in grain size, rather than grain number (Table 5). Although the amount of intercepted radiation between initiation and anthesis was significantly higher for the late-maturing hybrid in all experiments (Table
3), this was not reflected in differences in grain number. The differences in intercepted radiation were associated with longer preanthesis duration and greater leaf area

Table 4. Final harvest index for the treatments in each of the four experiments. The density associated with each treatment (plants $\mathrm{m}^{-2}$ ) is included in parentheses after the hybrid name. Not all treatments were included in each experiment.

\begin{tabular}{lcccc}
\hline & \multicolumn{4}{c}{ Experiment $\dagger$} \\
\cline { 2 - 5 } Hybrid (density, plants $\mathrm{m}^{-2}$ ) & 1 & 2 & 3 & 4 \\
\hline Pioneer S34 (16) & 0.55 & 0.46 & 0.56 & 0.53 \\
Pioneer S34 (8) & - & - & 0.57 & 0.52 \\
RS610 (16) & 0.53 & 0.42 & - & - \\
RS671 (16) & 0.49 & 0.43 & 0.47 & 0.48 \\
RS671 (8) & - & - & 0.47 & 0.49 \\
LSD hybrid (0.05) & 0.019 & NS & 0.02 & 0.02 \\
LSD density (0.05) & - & - & NS & NS \\
\hline
\end{tabular}

† Significant $(0.05)$ effects from pooled analysis across experiments were found for experiment $($ LSD $=0.02)$, hybrid $($ LSD $=0.02)$, and experiment $\times$ hybrid $(L S D=0.03)$. 
Table 5. Grain size (GS; $g 1000$ grain $^{-1}$ ) and grain number (GN; 1000 grain $\mathrm{m}^{-2}$ ) for treatments in each of the four experiments. The density associated with each treatment is included in parentheses after the hybrid name. Not all treatments were included in each experiment.

\begin{tabular}{|c|c|c|c|c|c|c|c|c|}
\hline \multirow[b]{3}{*}{ Hybrid (density, plants $\mathrm{m}^{-2}$ ) } & \multicolumn{8}{|c|}{ Experiment } \\
\hline & \multicolumn{2}{|c|}{1} & \multicolumn{2}{|c|}{2} & \multicolumn{2}{|c|}{3} & \multicolumn{2}{|c|}{4} \\
\hline & GS & GN & GS & GN & GS & GN & GS & GN \\
\hline Pioneer S34 (16) & 22.3 & 40.7 & 14.2 & 33.0 & 20.1 & 44.4 & 17.2 & 33.5 \\
\hline Pioneer S34 (8) & - & - & - & - & 18.6 & 43.5 & 16.8 & 32.6 \\
\hline RS610 (16) & 24.2 & 38.9 & 15.6 & 30.5 & - & - & - & - \\
\hline RS671 (16) & 18.8 & 44.8 & 14.7 & 35.5 & 17.8 & 43.6 & 18.0 & 35.4 \\
\hline RS671 (8) & - & - & - & - & 17.3 & 41.0 & 19.3 & 31.2 \\
\hline LSD hybrid (0.05) & 3.1 & NS & NS & NS & 1.1 & NS & 1.1 & NS \\
\hline LSD density $(0.05)$ & - & - & - & - & NS & NS & NS & NS \\
\hline
\end{tabular}

$\dagger$ Significant (0.05) effects from pooled analysis of GN across experiments were found for experiment (LSD = 3.7) only. Significant (0.05) effects from pooled analysis of GS across experiments were found for experiment $($ LSD $=1.2)$, hybrid $($ LSD $=1.1)$, and experiment $\times$ hybrid $($ LSD $=1.7)$.

development of the late-maturing hybrids. As grain number is more likely related to growth close to anthesis, as in other cereals (Fischer, 1985), the similar grain number among hybrids can be explained by their likely similar growth rates near anthesis. By this time, they had all achieved high levels of LAI, light interception, and crop growth.

As for differences in yield among experiments, differences among hybrids may also be explained by differences in both assimilation during grain filling and assimilate remobilization. In the high-yielding experiments (1 and 3 ), the late-maturing type had lower biomass increases between anthesis and maturity than the early maturing type (Table 3). As a consequence of being unable to take advantage of these high growth environment conditions, the late-maturing type experienced reduced grain size (Table 5) and HI (Table 4) in these experiments. It is not possible to discern whether this was caused by a limit on grain-filling rate for the late genotype (transport or sink limit) or some intrinsic loss of assimilation capacity during grain filling (source limit). It was also not possible to determine whether this outcome was associated with late maturity in general or was just an attribute of the particular genotype used in these experiments. In the low-yielding experiments (2 and 4), the late-maturing hybrid performed comparatively better (Table 2). There appeared to be less current assimilate and more remobilization contributing to yield in these experiments (Table 3 ). It is possible that the late-maturing type may have been better able to remobilize assimilate or had more available to remobilize in these conditions. This possibility was consistent with the similar or greater grain size measured for the latematuring type in Exp. 2 and 4 (Table 5). Again, however, it was not possible to discern whether this was a general effect related to maturity or just a characteristic of the particular genotype used here. Similar studies conducted with maturity differences in an otherwise common genetic background are needed to resolve this issue.

\section{Dynamics of Harvest Index}

The dynamics of HI during grain filling were defined by duration of the lag phase to the start of linear increase in $\mathrm{HI}$, slope of the linear increase, and time of cessation of the linear increase (Fig. 1). This broken linear model fitted data from each replicate of all treatments well $\left(R^{2}=0.93-0.99\right)$. Although there were some differences among experiments in duration of the lag phase, there were no significant effects of genotype or planting density in any of the four experiments (Table 6). Hence, this component did not explain the differences observed in grain yield and HI. There were also few significant differences within experiments in the time at cessation of the linear increase in HI (Table 7) although there were some differences among experiments and in patterns of hybrid variation across experiments. The significantly later finish for the low-density treatments in Exp. 3 was most likely caused by the enhanced number of fertile tillers (Table 3 ) and their slightly delayed development. The same trend was evident among density treatments in Exp. 4 although it did not reach statistical significance. The significantly earlier time at cessation of linear increase for the late-maturing hybrid over the early maturing hybrid in Exp. 4 was responsible for the lower final $\mathrm{HI}$ of that treatment (Table 4). This may have been associated with the lower temperature experienced by the late-maturing hybrid toward the end of grain filling in this experiment (Fig. 2) due to its delayed development relative to the early maturing hybrid. The same trend, although not significant, was evident among hybrids in Exp. 2, which also matured into cooling temperatures.

While timing issues had some important effects, many of the differences found in yield and HI among geno-

Table 6. Duration of the lag phase to start of linear harvest index increase, expressed as a fraction of the time from anthesis to physiological maturity, for treatments in each of the four experiments. The density associated with each treatment is included in parentheses after the hybrid name. Not all treatments were included in each experiment.

\begin{tabular}{lcccr}
\hline & \multicolumn{4}{c}{ Experiment $\dagger$} \\
\cline { 2 - 5 } Hybrid (density, plants $\mathrm{m}^{-2}$ ) & 1 & 2 & 3 & 4 \\
\hline Pioneer S34 (16) & 0.13 & 0.07 & 0.08 & 0.05 \\
Pioneer S34 (8) & - & - & 0.10 & 0.07 \\
RS610 (16) & 0.15 & 0.10 & - & - \\
RS671 (16) & 0.14 & 0.10 & 0.11 & 0.09 \\
RS671 (8) & - & - & 0.13 & 0.10 \\
$\quad$ LSD hybrid (0.05) & NS & NS & NS & NS \\
LSD density (0.05) & - & - & NS & NS \\
\hline
\end{tabular}

$\dagger$ Significant $(0.05)$ effects from pooled analysis across experiments were found for experiment $($ LSD $=0.04)$ and hybrid $($ LSD $=0.03)$. 
Table 7. Time at cessation of linear increase in harvest index, expressed as a fraction of the time from anthesis to physiological maturity, for treatments in each of the four experiments. The density associated with each treatment is included in parentheses after the hybrid name. Not all treatments were included in each experiment.

\begin{tabular}{lcccc}
\hline & \multicolumn{4}{c}{ Experiment $\dagger$} \\
\cline { 3 - 5 } Hybrid (density, plants $\mathrm{m}^{-2}$ ) & 1 & 2 & 3 & 4 \\
\hline Pioneer S34 (16) & 0.79 & 0.81 & 0.73 & 0.75 \\
Pioneer S34 (8) & - & - & 0.85 & 0.78 \\
RS610 (16) & 0.82 & 0.76 & - & - \\
RS671 (16) & 0.83 & 0.73 & 0.73 & 0.61 \\
RS671 (8) & - & - & 0.84 & 0.66 \\
$\quad$ LSD hybrid (0.05) & NS & NS & NS & 0.07 \\
LSD density (0.05) & - & - & 0.09 & NS \\
\hline
\end{tabular}

$\doteqdot$ Significant $(0.05)$ effects from pooled analysis across experiments were found for experiment $($ LSD $=0.09)$, hybrid $($ LSD $=0.07)$, density $($ LSD $=0.06)$, and experiment $\times$ hybrid $($ LSD $=0.12)$.

types and environments were associated with differences in the slope of the linear increase in HI (Table 8). This slope was highest in the high-yielding experiments (1 and 3), lowest in the lowest-yielding experiment (2), and intermediate in the other low-yielding experiment (4). The low slope in Exp. 2 was responsible for the much lower final HI in that experiment. This was probably caused by the very low temperatures experienced during grain filling in that late-sown experiment. Bange et al. (1998) described a similar response in sunflower. The differences in the slope of the linear increase in HI among experiments were consistent with the discussion about availability of current and remobilized assimilate during grain filling, presented earlier in relation to differences in yield and final HI. There was also a tendency for lower slope in the late-maturing hybrid in the highyielding experiments (1 and 3 ), although this was only significant in Exp. 3, and similar slope to other maturities in the low-yielding experiments (2 and 4). These effects generated the lower final $\mathrm{HI}$ found for the latematuring hybrid in Exp. 1 and 3 (Table 4). To retain a similar rate of increase in $\mathrm{HI}$, the late-maturing type, which generally had higher total biomass at anthesis (Table 3), would need to maintain a higher rate of total grain growth than the earlier-maturing type. This would generate higher yield if all other factors were the same, such as duration of the linear increase in HI. This trend occurred only in Exp. 2 and 4 (significant only in 4) when

Table 8. Slope of linear increase in harvest index $\left(d^{-1}\right)$ for treatments in each of the four experiments. The slope was calculated over the duration of the linear increase in harvest index (see Fig. 1). The density associated with each treatment is included in parentheses after the hybrid name. Not all treatments were included in each experiment.

\begin{tabular}{lcccc}
\hline & \multicolumn{4}{c}{ Experiment } \\
\cline { 2 - 5 } Hybrid (density, plants $\mathrm{m}^{-2}$ ) & 1 & 2 & 3 & 4 \\
\hline Pioneer S34 (16) & 0.025 & 0.015 & 0.024 & 0.020 \\
Pioneer S34 (8) & - & - & 0.023 & 0.019 \\
RS610 (16) & 0.023 & 0.014 & - & - \\
RS671 (16) & 0.021 & 0.014 & $\mathbf{0 . 0 2 1}$ & $\mathbf{0 . 0 2 0}$ \\
RS671 (8) & - & - & 0.019 & 0.019 \\
$\quad$ LSD hybrid (0.05) & NS & NS & 0.003 & NS \\
LSD density (0.05) & - & - & NS & NS \\
\hline
\end{tabular}

† Significant (0.05) effects from pooled analysis across experiments were found for experiment $($ LSD $=\mathbf{0 . 0 0 3})$, hybrid $($ LSD $=0.002)$, and density $(\mathrm{LSD}=\mathbf{0 . 0 0 2})$. it appeared that remobilization of preanthesis assimilate had greater influence on grain yield. Although the cessation of linear increase in $\mathrm{HI}$ occurred earlier for the late-maturing hybrid in those experiments (significant only in Exp. 4; Table 7), the duration of A-M was considerably longer for the late-maturing type due to confounding temperature effects (Table 1 and Fig. 2).

When data sets for the dynamics of HI during the grain-filling period from all experiments were plotted together using a standardized time (i.e., days after anthesis as proportion of days A-M) on the abscissa (Fig. 3), an appearance of general stability of the approach was evident. On average, the lag phase before onset of the linear increase in $\mathrm{HI}$ was 0.10 of the time from A-M. This was the same as the lag used by Chapman et al. (1993) in modeling HI dynamics in sunflower. The average time at cessation of linear increase in HI across all experiments was $76 \%$ of the time from A-M. Muchow (1990) found the cessation of HI increase for sorghum occurred after $67 \%$ of this interval had elapsed, but this related to experiments in tropical, high-temperature conditions. The average rate of $\mathrm{HI}$ increase across all experiments was $0.0198 \mathrm{~d}^{-1}$, which was $7 \%$ greater than the value of $0.0185 \mathrm{~d}^{-1}$ used by Hammer and Muchow (1994) in their sorghum crop model.

The general appearance of stability of the HI-time relationship has made this approach attractive in crop modeling. The attractiveness has been enhanced by the simplicity of the approach as predictions of grain number and grain size were not required and assimilate remobilization during grain filling was dealt with implicitly. Unfortunately, this appearance can be misleading. Small variations in rate of linear increase in HI per day and time at cessation of that increase have major effects on yield prediction (Hammer and Muchow, 1994). This is particularly the case when this approach is used on an actual time (days)-after-anthesis basis. These consequences on yield predictions arise because yield estimates involve the product of the estimated final HI with estimated total biomass. Bange et al. (1998) noted that employing a standardized time for the A-M period (as in Fig. 3) lessened these effects. In particular, in lowtemperature situations where HI slope was lowered but duration of A-M extended, yield prediction errors were

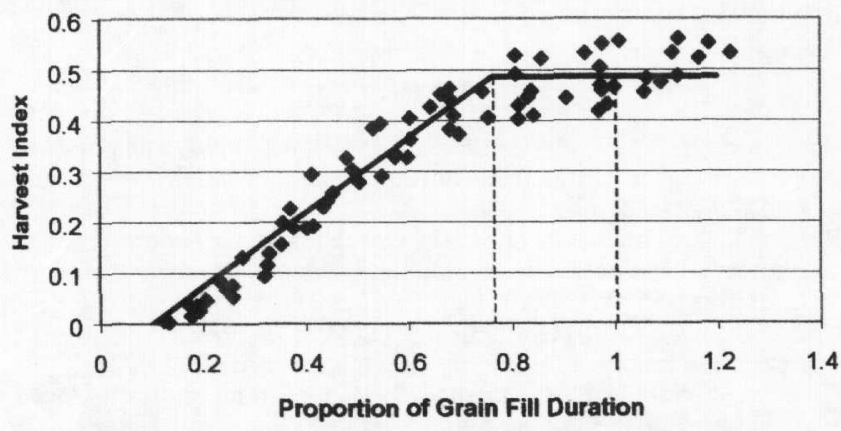

Fig. 3. Hybrid mean harvest index vs. proportion of grain fill duration for each of the four experiments (data from all experiments combined). The average lag phase and duration of the linear increase in harvest index are indicated. The origin on the abscissa represents $50 \%$ anthesis, and unity represents physiological maturity $(90 \%$ black layer). 
reduced using the standardized-time approach. However, that approach does not allow for any variation in final HI among environments and hybrids, which was substantial in these experiments $(0.42-0.57)$.

It seems clear that irrespective of the approach adopted, small variations in the components of final $\mathrm{HI}$ (Fig. 1) generate significant errors in yield prediction. The variations in slope of linear increase in HI (0.014$\left.0.025 \mathrm{~d}^{-1}\right)$ and time at cessation of that increase $(0.61-$ $0.85)$ due to effects of genotype (i.e., maturity) and environment (i.e., temperature) in this set of experiments were largely explained by variations in assimilation during grain filling and remobilization of preanthesis assimilate. Recent studies (Heiniger et al., 1997) have developed simple methods for predicting grain growth that are based on considerations of supply of, and demand for, assimilate during grain filling. In this method, remobilization and $\mathrm{HI}$ are emergent consequences of the balance between supply and demand. It is likely that development of such ideas has the potential to overcome the shortcomings found with the HI approach to yield prediction in crop modeling by replacing it with novel, simple, and robust methods to predict grain number and grain size.

\section{CONCLUSIONS}

Our results showed that there were significant genotype and environment effects on the dynamics of $\mathrm{HI}$ during grain filling in sorghum. While there was a firstorder stability in the dynamics of $\mathrm{HI}$, the variation introduced by these effects nonetheless limited the general applicability of the HI approach in yield prediction. The variations found in HI dynamics could be largely explained by differences in assimilation during grain filling and remobilization of preanthesis assimilate. Recent simple approaches to predicting grain growth based on balance between supply of, and demand for, assimilate during grain filling offer potential for dealing with the effects observed here in crop modeling.

\section{ACKNOWLEDGMENTS}

We thank Mr. David Butler for advice on statistical analyses and numerous staff members of APSRU who helped in establishing and maintaining the field experiments.

\section{REFERENCES}

Bange, M.P., G.L. Hammer, and K.G. Rickert. 1998. Temperature and sowing date affect the linear increase of sunflower harvest index. Agron. J. 90:324-328.

Bell, M.J.. T.E. Michaels, D.E. McCullough, and M. Tollenaar. 1994. Photosynthetic response to chilling in peanut (Arachis hypogaea L.). Crop Sci. 34:1014-1023.

Chapman, S.C., G.L. Hammer, and H. Meinke. 1993. A sunflower simulation model: I. Model development. Agron. J. 85:725-735.

Downes, R.W., and D.R. Marshall. 1971. Low temperature induced male sterility in Sorghum bicolor. Aust. J. Exp. Agric. Anim. Husb. $11: 352-356$

Eastin, J.D., J.H. Hultquist, and C.Y. Sullivan. 1973. Physiologic maturity in grain sorghum. Crop Sci. 13:175-178.

Fischer, K.S., and G.L. Wilson. 1975. Studies of grain production in Sorghum bicolor (L.) Moench: III. The relative importance of assimilate supply, grain growth capacity and transport system. Aust. J. Agric. Res. 26:11-23.

Fischer, R.A. 1985. Number of kernels in wheat crops and the influence of solar radiation and temperature. J. Agric. Sci. (Cambridge) 105: $447-461$.

Hall. A.E. 2001. Crop responses to environment. CRC Press, Boca Raton, FL.

Hammer, G.L., S.C. Chapman. and R.C. Muchow. 1996. Modelling sorghum in Australia: The state of the science and its role in the pursuit of improved practices. p. 43-61. In M.A. Foale, R.G. Henzell, and J.F. Kneipp (ed.) Proc. Australian Sorghum Conf., 3rd. Tamworth, NSW, Australia. 20-22 Feb. 1996. Occasional Publ. 93. Australian Inst. of Agric. Sci., Melbourne, VIC.

Hammer, G.L.. and R.C. Muchow. 1994. Assessing climatic risk to sorghum production in water-limited subtropical environments: $I$. Development and testing of a simulation model. Field Crops Res. 36:221-234.

Hammer, G.L.. T.R. Sinclair, K.J. Boote, G.C. Wright, H. Meinke, and M.J. Bell. 1995. A peanut simulation model: I. Model development and testing. Agron. J. 87:1085-1093.

Hammer, G.L., R.L. Vanderlip. G. Gibson, L.J. Wade, R.G. Henzell, D.R. Younger, J. Warren, and A.B. Dale. 1989. Genotype-byenvironment interaction in grain sorghum: II. Effects of temperature and photoperiod on ontogeny. Crop Sci. 29:376-384.

Heiniger, R.W., R.L. Vanderlip, S.M. Welch, and R.C. Muchow. 1997. Developing guidelines for replanting grain sorghum: II. Improved methods of simulating caryopsis weight and tiller number. Agron. J. 89:84-92.

McWilliam, J.R. 1983. Physiological basis for chilling stress and the consequences for crop production. p. 113-132. In C.D. Raper, JT., and P.J. Kramer (ed.) Crop reactions to water and temperature stresses in humid, temperate climates. Westview Press, Boulder, CO.

Moncur, M.W. 1981. Floral initiation in field crops-an atlas of scanning electron micrographs. Div. of Land Use Res., CSIRO. Canberra, ACT, Australia.

Muchow, R.C. 1988. Effect of nitrogen supply on the comparative productivity of maize and sorghum in a semi-arid tropical environment: III. Grain yield and nitrogen accumulation. Field Crops Res. 18:31-43.

Muchow. R.C. 1990. Effect of high temperature on the rate and duration of grain growth in field-grown Sorghum bicolor (L.) Moench. Aust. J. Agric. Res. 41:329-337.

Muchow, R.C.. G.L. Hammer, and R.L. Vanderlip. 1994. Assessing climatic risk to sorghum production in water-limited subtropical environments: II. Effects of planting date, soil water at planting, and cultivar phenology. Field Crops Res. 36:235-246.

Muchow, R.C., and T.R. Sinclair. 1991. Water deficit effects on maize yields modelled under current and greenhouse climates. Agron. J. 83:1052-1059.

Peacock, J.M. 1982. Response and tolerance of sorghum to temperature stress. p. 143-159. In Sorghum in the eighties. Proc. Int. Symp. on Sorghum. Patencheru, India. 2-7 Sept. 1981. ICRISAT. Patencheru. India.

Rayment, G.E., and F.R. Higginson. 1992. Australian handbook of soil and water chemical methods. Inkata Press. Melbourne. VIC, Australia

Rosenthal, W.D., R.L. Vanderlip, B.S. Jackson, and G.F. Arkin. 1989 SORKAM: A grain sorghum growth model. TAES Comput. Soft ware Documentation Ser. MP-1669. Texas Agric. Exp. Stn., College Station.

Spaeth, S.C., and T.R. Sinclair. 1985. Linear increase in soybean har vest index during seed-filling. Agron. J. 77:207-211. 